\title{
O PROGRAMA INSTITUCIONAL DE BOLSAS DE INICIAÇÃO À DOCÊNCIA E A EDUCAÇÃO DE JOVENS E ADULTOS: NOVOS OLHARES PARA A FORMAÇÃO DOCENTE EM EJA
}

\author{
Regina Magna Bonifácio de Araújo ${ }^{1}$
}

\begin{abstract}
RESUMO: O presente texto contempla a experiência vivenciada no Programa Institucional de Bolsas de Iniciação à Docência - PIBID, do subprojeto denominado Programa de Estímulo à Docência na Educação de Jovens e Adultos (PED/EJA), da Universidade Federal de Ouro Preto - UFOP e compartilha algumas reflexões sobre a importância deste projeto para a formação docente e para a Educação de Jovens e Adultos - EJA. Iniciado em 2011, este subprojeto atende todas as escolas que atuam na Educação de Jovens e Adultos no município de Mariana-MG, acolhendo cerca de 1300 alunos e alunas da EJA, 15 bolsistas da graduação e 03 supervisoras, professoras da rede municipal de ensino e que atuam como pedagogas nas escolas envolvidas com o projeto.
\end{abstract}

Palavras-chave: Educação de Jovens e adultos, docência, formação de professores

\section{INTRODUÇÃO}

Nas últimas duas décadas, muito se tem falado e escrito sobre a formação inicial e continuada de professores para a Educação Básica. No contexto das inúmeras reformas educacionais implantadas não apenas no Brasil, mas igualmente em vários países do mundo, esta formação tem sido discutida e avaliada, tendo em vista as mudanças significativas ocorridas nos processos produtivos, na organização do trabalho, nas comunicações e tecnologias, bem como nas políticas públicas. Todas essas mudanças vêm demandando uma formação diferenciada daquela que se praticava até o final do século passado,

\footnotetext{
${ }^{1}$ Professora Adjunta do Departamento de Educação da Universidade Federal de Ouro Preto UFOP. Pedagoga, mestre em Educação pela UFMG e doutora em Educação pela UNICAMP. Coordenadora do subprojeto PIBID em Pedagogia com ênfase na EJA. regina.magna@hotmail.com
} 
levando-se em consideração os fatores sociais, culturais, políticos e econômicos que constituem o contexto da estrutura social na qual os sujeitos estão inseridos. Neste cenário, ganha foco o Programa Institucional de Bolsa de Iniciação à Docência-PIBID, implantado pela Capes/MEC.

Com este texto pretendemos compartilhar a experiência do Subprojeto de Estímulo à Docência em EJA, o PIBID/PED-EJA ${ }^{2}$ da Universidade Federal de Ouro Preto. O PIBID vem se consolidando na busca de articulação entre os graduandos (Cursos de Licenciatura) e a escola de Educação Básica, representada pelos sistemas de ensino municipais e estaduais, em todo o território nacional, antecipando os vínculos entre licenciandos e comunidade escolar e promovendo experiências e saberes na vivência dos espaços educativos. Espera-se que este programa se transforme numa política de Estado, pois atualmente participam do PIBID 195 Instituições de Educação Superior de todo o país, que desenvolvem 288 projetos de iniciação à docência em aproximadamente 4 mil escolas públicas de Educação Básica e que envolve cerca de 49.321 bolsistas alunos das licenciaturas. Dada a importância deste projeto, algumas pesquisas surgem procurando investigar o impacto do PIBID na melhoria da qualidade da Educação Básica, dentre eles as de Wiebusch \& Andrade (2012); Wiebusch \& Ramos (2012); Santos et al (2011); Paredes \& Guimarães (2012); Carvalho (2011).

Os Editais publicados pela CAPES em 2010, 2011 e 2012 evidenciam esse crescente movimento, que compreendemos como de alcance político e social, o que tem oportunizado às instituições de educação superior, que ofertam cursos de Licenciatura, e no caso específico à UFOP, organizarem suas ações complementares na formação de seus alunos das diferentes licenciaturas por meio dos Projetos de Estímulo à Docência (PED-UFOP). Com o apoio dado pela Universidade - por parte da Reitoria e Pró-reitoria de Graduação - foi criado o Setor PED-UFOP para fazer a gestão dos projetos, com uma infraestrutura que sustenta e acompanha a realização dos mesmos. Este programa representa hoje um dos maiores em número de alunos contemplados com bolsas na instituição, bem como em abrangência, pois o

\footnotetext{
${ }^{2}$ O PIBID/PED-EJA, nome dado ao Programa de Estímulo à Docência em EJA na UFOP, é coordenado pela autora deste texto.
} 
mesmo se insere na rede municipal e estadual das cidades de Ouro Preto e Mariana, em todos os segmentos da Educação Básica e na modalidade EJA.

Os questionamentos sobre a formação de professores e a crescente desvalorização da profissão docente nos inquietam e nos mobilizam na busca de novos caminhos e sentidos que permitam a compreensão da prática educativa e a proposição de uma intervenção possível nos processos de formação docente. Enxergar a docência como uma escolha viável, acompanhála destes os primeiros semestres de formação e vivenciar situações que permitam aos alunos não apenas conhecer, mas mobilizar conhecimentos e saberes é o propósito da instituição ao participar do PIBID $^{3}$. Mesmo com os problemas que nossas escolas públicas vivenciam nos dias atuais, o alunado tem entendido que esses espaços educativos se constituem como um campo profissional interessante, complexo e desafiador. Diante desses fatos, os projetos construídos pela equipe de professores da UFOP têm como propósito articular o nosso contexto com os principais objetivos apresentados pelo PIBID, que pretende

incentivar a formação de docentes em nível superior para a Educação Básica; contribuir para a valorização do magistério; elevar a qualidade da formação inicial de professores nos cursos de licenciatura, promovendo a integração entre a Educação Superior e a Educação Básica; inserir os licenciandos no cotidiano de escolas da rede pública de educação; contribuir para a articulação entre teoria e prática necessárias à formação dos docentes, elevando a qualidade das ações acadêmicas nos cursos de licenciatura ${ }^{4}$

Um conjunto de ações foi pensado e construído na articulação entre as cinco estratégias gerais que compõem o plano de trabalho na UFOP do PIBIDPED/EJA e que apresentam como metas: 1) valorizar a licenciatura; 2) fortalecer as principais ações que já estão em andamento e proporcionar a construção de novas, a favor da promoção de experiências na docência por parte dos alunos; 3) estimular a iniciação à docência de bolsistas e não

\footnotetext{
${ }^{3}$ Projeto Institucional para o PIBID-UFOP, 2010.

${ }^{4}$ Portaria 260/2010/PIBID/CAPES, p. 03.
} 
bolsistas na EJA; 4) levar em conta as experiências e o contexto de cada escola envolvida; 5) estruturar um plano para acompanhamento e avaliação do

\subsection{Projeto de Estímulo à Docência em EJA}

Este subprojeto que integra o PIBID na UFOP envolve escolas públicas que atuam com a Educação de Jovens e Adultos - EJA, do município de Mariana- MG e alunos/as do curso de Pedagogia da UFOP. O projeto objetiva, em primeiro lugar, desenvolver a iniciação à docência de jovens e adultos, privilegiando a formação para o magistério nesta modalidade de ensino, no sistema público de educação, pois os alunos-bolsistas têm como tarefa integrar-se às turmas de Educação de Jovens e Adultos - EJA. Além disto, terão oportunidade de vivenciar experiências metodológicas e práticas docentes de caráter interdisciplinar, pois o projeto conta com a colaboração dos bolsistas de outros cursos, como Letras, Nutrição e Farmácia, além do envolvimento de todas as áreas e segmentos da Educação Básica. Da mesma forma, a presença dos futuros docentes e o trabalho integrado com as escolas visam contribuir para a elevação do padrão de qualidade da Educação Básica, em especial no trabalho com jovens e adultos.

\section{ESTIMULAR A INICIAÇÃO À DOCÊNCIA E CONSIDERAR O CONTEXTO}

O Programa de Estímulo à Docência em EJA aqui apresentado está em consonância com os objetivos do PIBID, sem, no entanto, se afastar dos objetivos desenvolvidos ou em desenvolvimento em nossas licenciaturas. Em outras palavras, as experiências já adquiridas e a reflexão sobre as licenciaturas para reformulações e melhorias das ações - em especial, aquelas voltadas para o incentivo à docência em EJA, também se colocam com suas finalidades e objetivos (locais) a serem articulados aos objetivos mais amplos do PIBID.

Este subprojeto envolveu, além das estratégias já expostas, a participação de vários atores. $\mathrm{Na}$ elaboração e implementação do projeto temos, 
primeiramente, o pessoal da Pró-reitoria de Graduação dando suporte pedagógico e técnico. Em um segundo momento, os coordenadores que estruturaram as bases para os processos de elaboração e implantação dos subprojetos nas escolas. Igualmente, toda a equipe do PIBID/PED-UFOP ligado à Pró-reitoria de Graduação -, a secretária que lá atua, os coordenadores, os supervisores e os alunos bolsistas. Por último, mas não menos importante, o pessoal da comunidade escolar (pedagogas, professores e alunos), público que será igualmente afetado pelo projeto.

Fazem parte deste subprojeto também ações e atividades de várias naturezas: contato com as escolas e a Secretaria Municipal de Educação do município favorecido; oficinas pedagógicas para supervisores e bolsistas; planejamentos específicos para cada área e para cada escola; organização de reuniões periódicas com bolsistas e supervisores para a discussão do andamento do projeto; elaboração de materiais pedagógicos; acompanhamento e controle dos gastos com o projeto e a produção de relatórios semestrais e anuais.

A complexidade que envolve o PIBID-PED/EJA, como se pode notar, não é pequena. Nossas ações têm a função de, por um lado, monitorar e avaliar o subprojeto e, por outro, produzir reflexões, promovendo espaços para discussão acerca das mesmas e construir textos analíticos sobre todo o processo, como também sobre os resultados alcançados. As ações de acompanhamento e avaliação se fazem necessárias para que possamos realizar exames regulares em relação à execução do projeto, procurando refletir se as ações e atitudes estão ajudando a alcançar os objetivos estabelecidos e os resultados esperados e se as verbas estão sendo adequadamente empregadas. Com isso, esperamos rever ações e atitudes na direção de melhorar nossas propostas de formação inicial para a docência em EJA. As avaliações realizadas ao longo do desenvolvimento do projeto, bem como a avaliação final, como continuidade do processo de acompanhamento, nos ajudará a analisar se nosso subprojeto foi eficaz, produzindo os efeitos desejados e planejados por seus atores e se foi efetivo, ou seja, se os efeitos alcançados permaneceram mesmo após o término do projeto. A produção de textos, pelos bolsistas e coordenação, terá como função divulgar para a 
comunidade acadêmica nossos esforços, buscando com isso contribuir com a produção científica em torno do incentivo à docência em EJA.

A proposta desenvolvida com esses alunos e alunas, bolsistas do PIBID, é acompanhada pela coordenadora deste projeto e pelos professores supervisores nas escolas públicas convidadas, que são as pedagogas selecionadas para este acompanhamento. O trabalho dos alunos bolsistas demanda doze horas semanais de dedicação às ações do PIBID/PED-EJA, sem prejuízo das atividades discentes regulares, num trabalho integrado com a coordenadora e as supervisoras.

Os interesses de formação propagados no curso de Pedagogia e demais licenciaturas em relação à atenção que deve ser dada à educação de jovens e adultos aliam-se aos interesses presentes no PIBID/PED-UFOP, ou seja, o de valorizar as licenciaturas; estimular uma boa e planejada iniciação à docência; conhecer bem o contexto escolar; acompanhar e avaliar o desenvolvimento dos envolvidos, bem como do projeto. Além de guardarem proximidade com o proposto pelo PIBID, como objetivos orientadores, que podem ser descritos: “incentivar a formação de docentes em nível superior para a Educação Básica; contribuir para a valorização do magistério; elevar a qualidade da formação inicial de professores nos cursos de licenciatura, promovendo a integração entre a Educação Superior e a Educação Básica; inserir os licenciandos no cotidiano de escolas da rede pública de educação; contribuir para a articulação entre teoria e prática necessárias à formação dos docentes, elevando a qualidade das ações acadêmicas nos cursos de licenciatura" 5 . Como desdobramento e consequência desses interesses comuns, nossos objetivos podem ser descritos da seguinte maneira:

1. Preparar os alunos de Licenciatura em Pedagogia para o exercício da prática pedagógica com jovens e adultos, em ações interdisciplinares com bolsistas de outros cursos da UFOP;

2. Orientar os bolsistas na direção de se tornarem agentes multiplicadores a favor de uma prática pedagógica consciente e planejada, na própria área e com

\footnotetext{
${ }^{5}$ Portaria 260/2010/PIBID/CAPES, p. 03.
} 
o trabalho com jovens e adultos, como também nas outras áreas envolvidas com o PIBID/PED-UFOP;

3. Estimular o maior número possível de alunos a atuarem na educação de jovens e adultos;

4. Produzir e registrar conhecimentos em torno da educação de jovens e adultos, promovendo futuros avanços em torno do tema.

\section{UM NOVO OLHAR PARA UMA ANTIGA REALIDADE}

O foco que este subprojeto de Pedagogia pretende dar à EJA parte do princípio e do reconhecimento de que a educação possibilita ao individuo jovem e adulto retomar seu potencial, desenvolver suas habilidades, confirmar competências adquiridas na educação extra-escolar e na própria vida, com vistas a uma inserção mais efetiva na sociedade e um domínio em nível técnico e profissional mais qualificado. A Educação de Jovens e Adultos representa, enquanto modalidade da Educação Básica, uma possibilidade que pode efetivar um caminho, por meio do desenvolvimento de todas as pessoas, de todas as idades. Planejar esse processo é uma grande responsabilidade social e educacional, cabendo a toda comunidade educativa e, em especial ao professor, o papel de mediar o conhecimento, para que todos possam ter uma base sólida de formação.

Ao conferirmos os dados estatísticos do analfabetismo, apresentado pelo IBGE, no censo de 2010, ainda nos deparamos com um quadro que, embora reflita uma redução do índice de pessoas analfabetas no país, ainda é preocupante: 


\section{Evolução das taxas de analfabetismo por região}

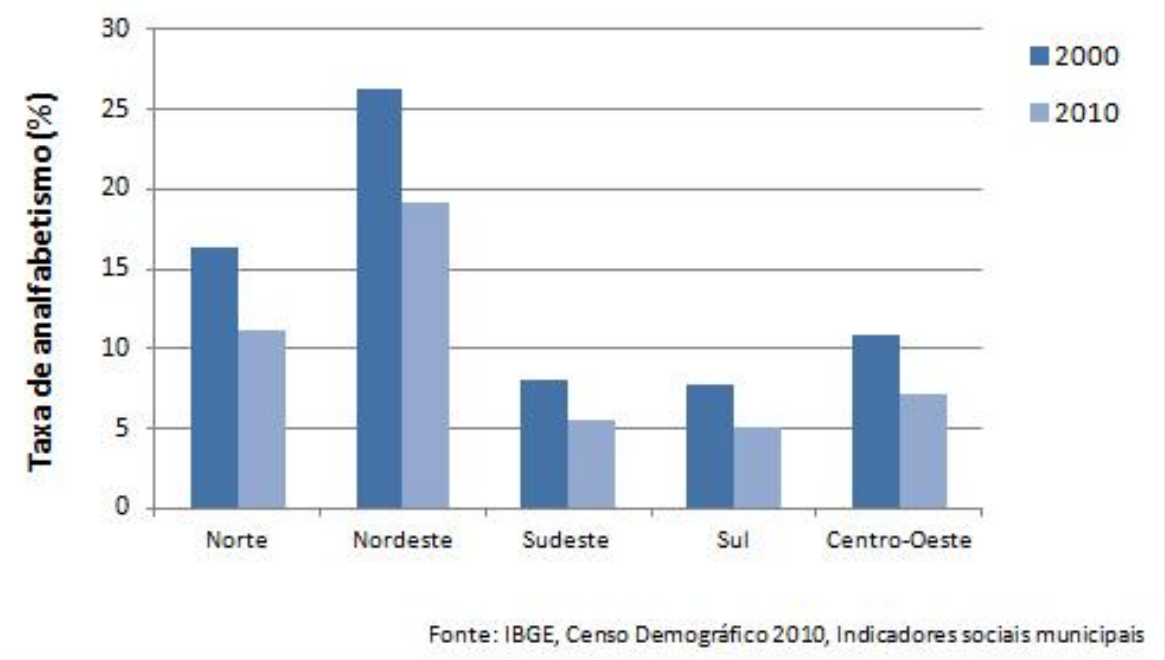

$\mathrm{Na}$ Região Sudeste, a situação se apresenta um pouco melhor, mas ainda denunciadora da pouca atenção que damos à educação, em especial à educação das pessoas jovens e adultas, o que pode ser confirmado no quadro abaixo, que destaca o índice de analfabetismo por faixa etária. Mais de oito milhões de brasileiros, à margem do processo educativo, representam o pouco valor dado à educação de uma maneira geral pelo poder público e nos mobiliza ao compromisso para com a EJA e com a formação da docência para esta modalidade de ensino. 


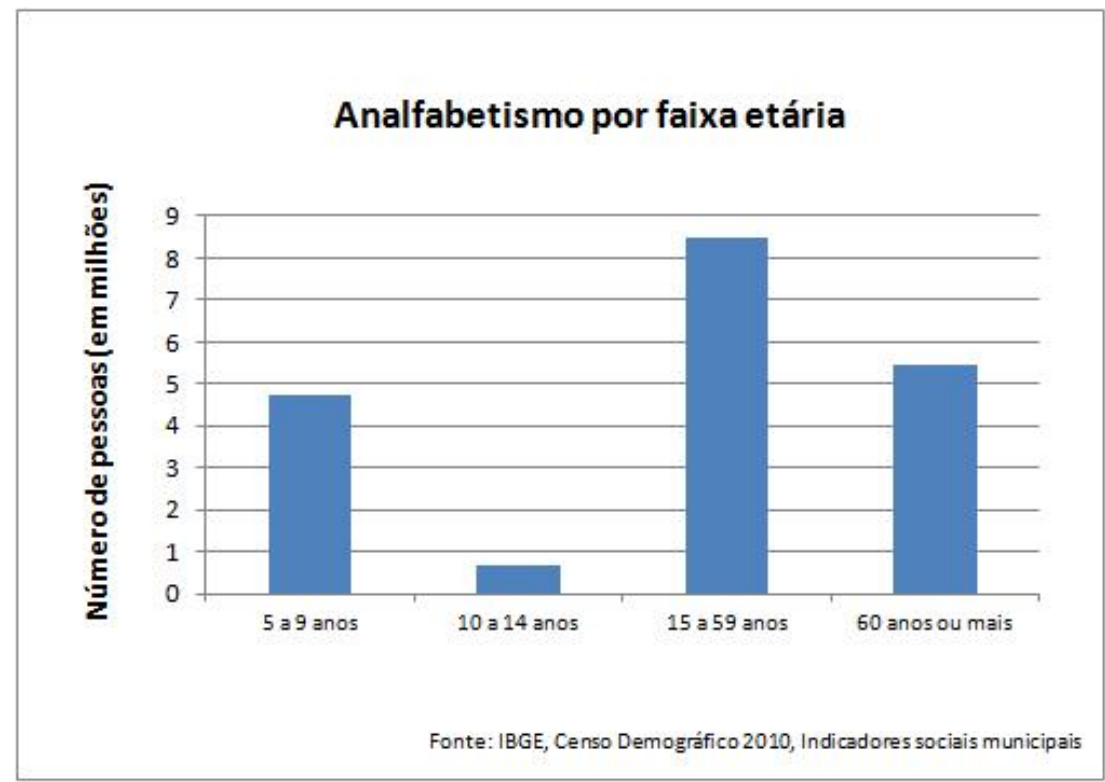

O subprojeto PIBID-PED/EJA se organizou pensando em cada jovem e adulto do município de Mariana, que retorna à escola, propondo desenvolver ações e atividades que devem se articular com aquelas que estão previstas no projeto pedagógico de cada instituição. Essas ações e atividades, orientadas a partir das cinco estratégias gerais, já apresentadas na introdução deste texto, levam em consideração, também, as especificidades desses sujeitos para os quais elas se voltam, considerando quem são, suas histórias de vida, trajetórias e necessidades.

Atualmente, Mariana possui cerca de 54.179 habitantes, dados estimados em 2010 e um número significativo de instituições de ensino, sendo 34 Préescolas, 40 escolas de Ensino Fundamental, 09 de Ensino Médio e 07 de Ensino Superior. Mesmo apresentando um dos menores índices de analfabetismo do país, cerca de $1 \%$ da população, a cada dia aumenta a matrícula na EJA em escolas da rede municipal, com a presença daqueles que não puderam freqüentar a escola ou mesmo que fracassaram no ensino regular, por freqüentes retenções ou evasão.

É para esta realidade que este subprojeto busca construir suas primeiras discussões e ações, reconhecendo a desatenção dada a esta modalidade de 
ensino, e que é procurada pelos "mais pobres, os extratos mais baixos da hierarquia social, os afrodescendentes, aqueles que vivem nas zonas rurais e nas periferias dos grandes centros urbanos" (HADADD, 2000).

\section{A PRÁTICA DO PIBID-PED/EJA}

Buscamos no processo seletivo priorizar a participação, como bolsistas, de alunos e alunas que estavam cursando a Pedagogia, dando preferência àqueles que tinham por cursar, no mínimo, três períodos e que poderiam contribuir como multiplicadores em relação aos outros alunos que não participavam como bolsistas, podendo se integrar ao projeto antes mesmo da realização do estágio supervisionado ou em seu início. A ação estratégica, nesse sentido, dividiu-se em três passos: $\left.1^{\circ}\right)$ como bolsistas PIBID, inseri-los na realidade escolar antes de fazerem seus estágios ou no início dos mesmos; $\left.2^{\circ}\right)$ fazer com que os bolsistas sejam catalisadores, multiplicadores e disseminadores da importância e riqueza de se exercer a docência na EJA; 3ำ) como alunos das disciplinas de estágio, e não mais como bolsistas, ter a vivência docente em sala de aula da EJA com maior autonomia e segurança. Acreditamos que com o devido acompanhamento e supervisão, com a chance de conviverem com professores experientes e de aprenderem com eles, com a participação na elaboração de propostas de ensino, o estágio deixará de ser apenas o único momento de experimentação da prática docente na EJA, para se transformar em um momento de grande contribuição em suas formações. Além disso, por meio de eventos abertos à comunidade (seminários, reuniões, relatos de experiência), buscamos promover o compartilhamento de experiências vividas pelos coordenadores, supervisores e bolsistas entre si e com os demais estudantes e que não participam diretamente do PIBID/PEDUFOP como um todo.

Acreditamos que o nosso papel como formadores não é produzir conhecimento na Universidade para implementá-lo nas escolas de Educação Básica, desconsiderando os saberes e as experiências dos professores e alunos que nelas se encontram. Entendemos que a realidade é diversa, multifacetada e que cada unidade escolar que atua com a EJA tem de vencer 
seus próprios desafios por meio de diferentes formas de ação a serem consideradas. Nossa meta é constituir um espaço de colaboração no qual cada esfera - formação inicial para a docência, trabalho com a comunidade escolar, as práticas de pesquisa - possa oferecer sua contribuição e proporcionar elementos para o crescimento de todos. Nesta perspectiva o subprojeto PIBIDPED/EJA foi pensado.

$\mathrm{Na}$ construção desse plano de trabalho foi previsto uma sondagem inicial junto aos alunos da EJA visando a identificação de seu perfil, o conhecimento de sua realidade, dos motivos que os levaram a deixar a escola ou mesmo de nunca nela entrar, das causas do retorno aos estudos e dos pontos conflitantes e obstáculos encontrados na aprendizagem em todas as áreas.

No município de Mariana participam do subprojeto PIBID-PED/EJA as escolas municipais no quadro abaixo relacionadas, num total de 1302 alunos.

\begin{tabular}{|c|c|c|}
\hline $\begin{array}{l}\text { Nome e endereço das } \\
\text { escolas da rede pública } \\
\text { de Educação Básica } \\
\text { (listar todas } \\
\text { participantes do } \\
\text { subprojeto institucional) }\end{array}$ & $\begin{array}{l}\text { № de alunos } \\
\text { matriculados na } \\
\text { escola considerando } \\
\text { apenas o Nível de } \\
\text { Licenciatura em EJA }\end{array}$ & $\begin{array}{l}\text { Último IDEB } \\
(2009)\end{array}$ \\
\hline $\begin{array}{l}\text { Nome: E. M. Monsenhor } \\
\text { Cota } \\
\text { Endereço: Pc Juscelino } \\
\text { Kubitschek, s/n - Mariana }\end{array}$ & 507 (a e b) & $4,9 / 4,5$ \\
\hline $\begin{array}{l}\text { Nome: E. M. Wilson } \\
\text { Pimenta } \\
\text { Endereço: Rua L, } 0 \text { - Sto } \\
\text { Antonio } \\
\text { Mariana-MG }\end{array}$ & $172(a)$ & 3,1 \\
\hline $\begin{array}{l}\text { Nome: Centro } \\
\text { Educacional Municipal } \\
\text { Padre Avelar - CEMPA } \\
\text { Endereço: Rodovia do } \\
\text { Contorno, 327, bairro } \\
\text { Colina - Mariana }\end{array}$ & 623 (a e b) & $4,6 / 4,2$ \\
\hline
\end{tabular}


Uma das principais marcas da comunidade atendida pela EJA é a diversidade: de idades, de experiências, de expectativas. Entretanto, muitas das histórias de vida destes sujeitos apresentam alguns traços em comum, em especial, as marcas da exclusão e das dificuldades de realizar ou mesmo de concluir os estudos na idade regular.

Os dados que apresentaremos a seguir, coletados pelos bolsistas do PIBID-PED/EJA, na fase inicial de sondagem, mostram um pouco deste perfil Responderam ao questionário de sondagem 509 alunos, sendo que destes a maioria, ou seja, 53\% possuem idade entre 18 e 30 anos. Uma pequena parcela, embora significativa e que representa 13\% dos alunos entrevistados, possuem mais que 41 anos, conforme ilustrado no gráfico acima. O que confirma a "juvenilização" (CARRANO, 2007) das classes da EJA, também neste município, fenômeno que se repete em todo país.

Temos ainda outros aspectos que compõem a diversidade dos alunos e alunas da EJA, além das

diferenças quanto à idade. No total de alunos que freqüentam as classes de EJA 53\% são mulheres e 47\% são homens, conforme o gráfico abaixo. É interessante o fato de termos um número significativo de homens, quando até poucos anos atrás as classes de EJA eram de maioria feminina. Para Souza e Fonseca (2009),

as mulheres tem-se constituído um público específico da Educação de Pessoas Jovens e Adultas - EJA, seja pela maior amplitude da experiência feminina de não acesso à educação, seja pela sua maior inserção em projetos de escolarização, que passam a atender mulheres em sua grande maioria, mais adaptáveis que parecem ser aos rituais e à disciplina da vida escolar. (p.02).

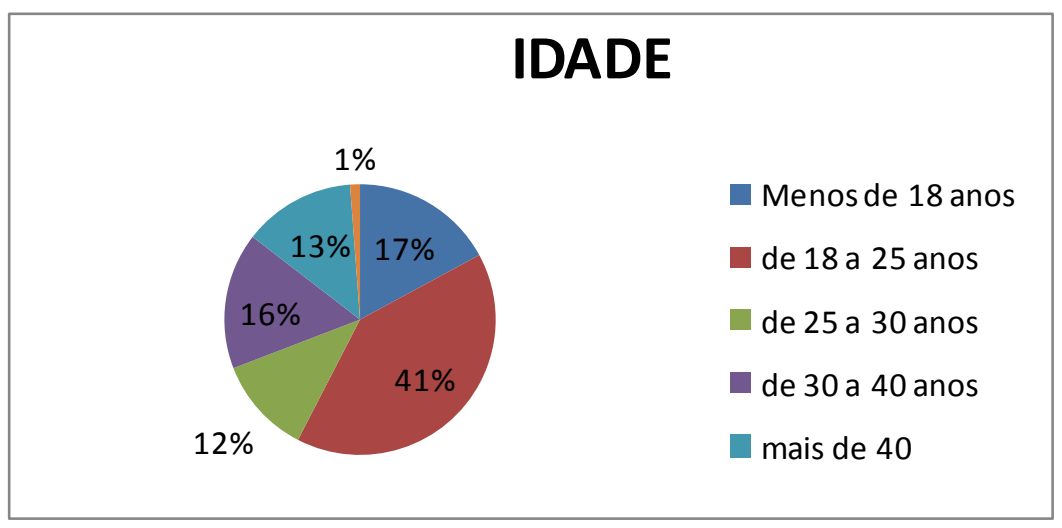


Além das informações sobre série/ano que estudam e tempo médio que os alunos freqüentam a EJA, os questionários trazem os motivos de abandono e retorno à escola. A maioria destes alunos já esteve numa escola regular e alguns já freqüentaram classes de EJA em outras instituições. O motivo principal que levou estes jovens e adultos a abandonarem os estudos está relacionado ao fato de que as famílias precisam de ajuda, em algumas situações com o "serviço da roça", e eles tinham que trabalhar para ajudar nas despesas (92\%), sendo que alguns alegam responsabilidades familiares, como cuidar dos filhos (3\%) e outros nunca foram à escola porque ninguém obrigava $(1 \%)$.

"Para aprender a ler, escrever e ajudar os filhos com as atividades escolares", "para reparar o tempo perdido", ou "para manter-se no emprego" ou mesmo "para conseguir um emprego" foram os principais motivos que levaram esses mesmos alunos de volta aos estudos. Cerca de $25 \%$ indicam o desenvolvimento pessoal e a vontade de aprender como o fator que os fizeram retornar à escola. Entretanto, o trabalho é um importante fator de motivação para este retorno, ou seja, cerca de $47 \%$ destes jovens e adultos afirmaram que pretendem conseguir um emprego ou buscam uma melhor qualificação profissional.

Estes dados iniciais coletados para este subprojeto foram utilizados, juntamente com outras respostas do questionário, como orientadores para a construção de cada ação nas escolas participantes. Com este conhecimento propomos

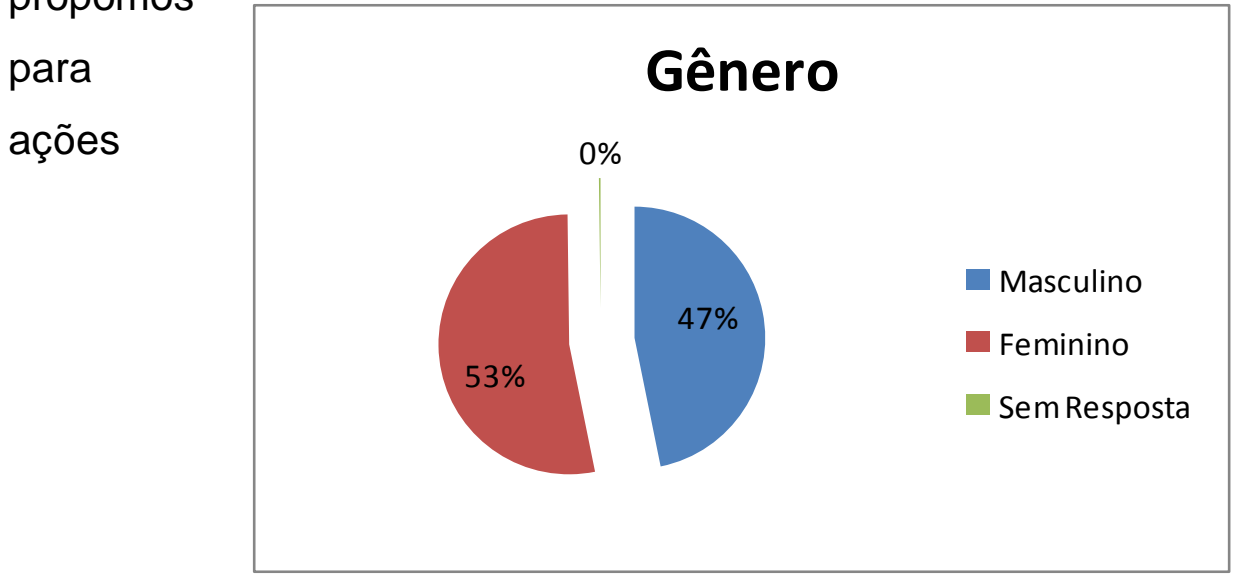
considerar, nortear as

planejadas, a estrutura e o funcionamento da EJA nessas escolas, a organização das turmas, a organização da aprendizagem e sua progressão ao 
longo do ensino fundamental, a seleção de temas e conteúdos de aprendizagem e a forma como as relações interpessoais se estabelecem dentro da escola e as condições de permanência dos mesmos nas escolas.

Após este levantamento, iniciamos a compreensão da demanda específica de cada escola, por meio de conversas com a coordenação pedagógica, reuniões com os professores e com os alunos. A partir daí foram construídas e implementadas ações estratégicas com o objetivo de promover e incentivar a prática docente ${ }^{6}$ de nossos licenciandos, o aprimoramento dos coordenadores, supervisores e dos professores das escolas diretamente envolvidos $^{7}$ e, por consequência, a busca da melhoria da qualidade da educação dos jovens e adultos na região.

A construção dos planos de trabalho, incluindo a montagem conjunta de um cronograma de atividades foi desenvolvida em cada uma das escolas, respeitando suas realidades e especificidades. Essa construção aconteceu em conjunto com os professores supervisores de cada instituição e é retomada periodicamente, no início de cada semestre letivo. Assim, alguns projetos foram desenvolvidos nesses dois anos de atuação:

\begin{tabular}{|l|l|l|}
\hline Escolas & Projetos & $\begin{array}{l}\text { Segmentos } \\
\text { atendido na } \\
\text { EJA }\end{array}$ \\
\hline $\begin{array}{l}\text { E. M. Monsenhor } \\
\text { Cota }\end{array}$ & $\begin{array}{l}\text { Alfabetização por meio das } \\
\text { Mídias Digitais }\end{array}$ & $\begin{array}{l}1 \text { o Segmento do } \\
\text { Ensino } \\
\text { Fundamental na } \\
\text { EJA }\end{array}$ \\
\hline
\end{tabular}

${ }^{6}$ Prática docente, neste contexto, entendida como toda a vivência que o espaço escolar pode oferecer como: o acompanhamento de aulas, a participação em Conselhos de Classe, as reuniões de professores e pais, a construção do Projeto Político Pedagógico,, etc., sem que esta participação implique atividades de substituição do professor de classe ou eventuais carências de pessoal nas escolas.

Ao longo desses dois anos de PIBID/PED-UFOP, observamos que precisamos também formar melhor aquele que forma. Tanto os coordenadores como os supervisores apontaram a necessidade de se aperfeiçoarem em questões relacionadas à formação de professores para EJA, ao planejamento, às metodologias, ao currículo e à avaliação nesta modalidade de ensino. 


\begin{tabular}{|c|c|c|}
\hline Wilson Pimenta & $\begin{array}{l}\text { 1. Curso de Inglês } \\
\text { 2. Cultura em debate } \\
\text { 3. Círculo de Cultura }\end{array}$ & $\begin{array}{l}\text { Todos os } \\
\text { segmentos da EJA }\end{array}$ \\
\hline $\begin{array}{l}\text { Centro Educacional } \\
\text { Municipal Padre } \\
\text { Avelar - CEMPA I }\end{array}$ & $\begin{array}{l}\text { 1. Projeto Alfabetizando } \\
\text { 2. Projeto Filosofando }\end{array}$ & $\begin{array}{l}\text { 1. 10 Segmento do } \\
\text { Ensino } \\
\text { Fundamental na } \\
\text { EJA } \\
\text { 2. Ensino Médio- } \\
\text { EJA }\end{array}$ \\
\hline CEMPA II & Escrever para Aprender & $\begin{array}{l}2^{\circ} \text { Segmento do } \\
\text { Ensino } \\
\text { Fundamental na } \\
\text { EJA }\end{array}$ \\
\hline
\end{tabular}

Além do desenvolvimento desses projetos, incentivamos, juntamente com as supervisoras nas escolas, a participação dos bolsistas em atividades do cotidiano escolar e, sobretudo, no acompanhamento das práticas pedagógicas com jovens e adultos, em conformidade com os planos de trabalhos e a realidade de cada unidade escolar.

Para o acompanhamento das ações e atividades planejadas, promovemos encontros semanais entre bolsistas, coordenadora do subprojeto, bem como encontros quinzenais com os professores supervisores. O objetivo desses encontros é o de refletir em conjunto sobre o encaminhamento de cada projeto e das suas ações, bem como operar alterações e retificações sempre que necessárias. Parte deste tempo é empregado na formação continuada dos integrantes da equipe por meio de leitura e discussão de textos e da legislação nacional, estadual e municipal referentes à EJA.

A Constituição Federal de 1988 e a LDB/1996, conferem aos municípios a responsabilidade do Ensino Fundamental e estabelecem que aos sistemas de ensino cabem assegurar gratuitamente aos jovens e adultos, que não puderam efetuar os estudos na idade regular, oportunidades educacionais apropriadas, considerando as características dos alunos, seus interesses, 
condições de vida e de trabalho. Também cabem a esses sistemas de ensino, viabilizar e estimular o acesso e a permanência do trabalhador na escola, mediante ações integradas e complementares entre os diversos setores das esferas públicas, sejam elas municipais, estaduais ou federal.

Esperamos com as ações do PIBID-PED/EJA contribuir com 0 município de Mariana, bem como com os demais municípios do entorno e que integram a Região dos Inconfidentes em Minas Gerais, e com as unidades de ensino que recebem nossos bolsistas, na tarefa de auxiliar na promoção do acesso à cidadania e o despertar do interesse pela elevação da escolaridade e do Índice de Desenvolvimento da Educação Básica.

\section{REFERÊNCIAS}

BRASIL. Ministério de Educação e Cultura. LDB - Lei no 9394/96, de 20 de dezembro de 1996. Estabelece as diretrizes e bases da Educação Nacional. Brasília: MEC, 1996.

BRASIL. Constituição (1988). Constituição da República Federativa do Brasil. Brasília, DF, Senado, 1998.

BRASIL. Decreto 7.219, de 24 de junho de 2010. Dispõe sobre o Programa Institucional de Bolsa de Iniciação à Docência - PIBID e dá outras providências. Acessado em 12/ jan/2011 e disponível em: www.capes.gov.br/images/stories/download/diversos/DecretoPIBID_240610.pd f.

CARRANO, Paulo. Educação de Jovens e Adultos e Juventude: o desafio de compreender os sentidos da presença dos jovens na escola da "segunda Chance". Revista de Educação de Jovens e Adultos, v. 1, n. 0, p. 1-11 Belo Horizonte, 2007.

HADDAD, S. O Estado da Arte das pesquisas em educação de Jovens e Adultos no Brasil: a produção discente de pós-graduação em educação no período de 1986-1998. São Paulo: AçãoEducativa, 2000.

SOUZA, Maria Celeste Reis Fernandes de \& FONSECA Maria da C. Ferreira Reis. Conceito de Gênero e Educação Matemática: Bolema: Boletim de Educação Matemática. Rio Claro (SP), Ano 22 no. 33, 2009, p.29 a 45. 
* Recebido em Maio de 2013.

* Aprovado em junho de 2013. 